\title{
EDITORIAL
}

\section{Surgimiento de Avances en la Enseñanza de Física}

DOI: https://doi.org/10.36411/AEF.1.1.1

Con este número se inaugura la revista Avances en la Enseñanza de la Física (AEF). Publicación electrónica, de acceso abierto, arbitrada y de frecuencia semestral editada por el Departamento de Física del Consejo de Formación en Educación, perteneciente a la Administración Nacional de Educación Pública (ANEP) del Uruguay.

Nuestra revista tiene como objetivo principal difundir resultados y reflexiones provenientes de investigaciones y experiencias en el área de Enseñanza de la Física y Educación en Ciencias. Se pretende contribuir así a la producción de conocimientos en el área y hacer aportes a la formación de investigadores y docentes, que propicien el desarrollo de acciones educativas responsables y comprometidas con la mejora de la educación científica y el bienestar social.

Esta publicación pretende contribuir y complementar los espacios editoriales ya existentes a nivel internacional, al tiempo que aspira a transformarse en un instrumento para los docentes e investigadores de nuestro país, interesados en compartir sus experiencias de aulas y trabajos de investigación.

Está dirigida a investigadores, educadores, profesores y estudiantes interesados en avances y revisiones acerca de la enseñanza de la Ciencia y de la Física en particular, con el fin último de contribuir a la mejora de las prácticas de los docentes que redunden en incentivar el gusto por la ciencia, el desarrollo del espíritu crítico y la cultura científica en nuestros estudiantes.

Publicamos en este primer número cuatro trabajos de investigación con autores de tres países (Argentina, Brasil y Uruguay)

AEF Tenderá a cumplir con los estándares internacionales de calidad editorial a saber:

- Adopción del software OJS (Open Journal System) de gestión editorial en línea, interoperable y con tecnología adaptada a dispositivos móviles.

- Riguroso proceso de evaluación por pares doble ciego

- Utilización de herramientas antiplagio de CROSSREF, Similarity Check

- Integración de identificadores digitales como DOI, ORCID

- Normalización en aspectos formales y de contenidos de la revista

- Optar a índices y bases de datos regionales e internacionales

Nos resta simplemente agradecer tanto a autores como revisores quienes han contribuido con su trabajo, permitiendo que esta publicación se haya hecho realidad en el presente año.

Dr. Stelio Haniotis

Director editorial 